\title{
DIMENSIÓN CONSTITUCIONAL DE LA PROFESIONALIZACIÓN DE LAS FUERZAS ARMADAS
}

MIGUEL HERRERO DE MIÑÓN 


\section{DIMENSIÓN CONSTITUCIONAL \\ DE LA PROFESIONALIZACIÓN DE LAS FUERZAS ARMADAS}

POR

MIGUEL HERRERO DE MIÑÓN

1. La profesionalización consiste en sustituir unas Fuerzas Armadas, cuyo potencial humano se fundamenta en el servicio militar obligatorio, para la mayor parte de las clases de tropa, por otras basadas exclusivamente en el reclutamiento voluntario, tanto de los soldados como de los jefes y oficiales, que hacen de ello su medio de vida según la acepción vulgar y jurídica de profesión ${ }^{1}$. ¿Un sistema semejante es constitucional o no, a tenor de nuestra vigente norma fundamental de 1978?

El problema tiene una gran importancia en sí mismo, como opción política y como cuestión técnica. Pero, además, abordado sub specie constitutionis adquiere una dimensión nueva y mayor que afecta, como se verá, a los fundamentos mismos de nuestra concepción del Estado y, en consecuencia, de su Teoría.

El rigor en el planteamiento dogmático hace que los problemas políticos de fondo salgan a nueva luz. Sólo así el derecho público en general y el derecho constitucional en particular, concebidos como técnica de solución de conflictos, pero nada más y nada menos que de

1 "Empleo, facultad u oficio que cada uno tiene y ejerce públicamente», según el DRAE, concepto recibido por la jurisprudencia; cfr. Souviron MORENILLA, La configuración jurídica de las profesiones tituladas en España y en la Comunidad Europea, Madrid, 1988, págs. 25 y ss. 
conflictos de poder, adquiere plena eficacia y sentido. Lo demás, decía Triepel en su famoso discurso sobre "Política y Derecho", es un cascarón vacío.

Hoy día el problema de la defensa nacional y sus medios humanos y materiales viene determinado por dos factores. De un lado, por un imperativo de eficacia que exige capacitación profesional y dotación económica, determinado, a su vez, por un entorno estratégico que, a mi juicio, con el fin de la Guerra Fría, no se ha hecho menos hostil, sino al contrario, porque al cancelarse la bipolarización surgen nuevos desafíos - cuando no amenazas - en escenarios que nos son próximos $y$, además, posibilidades en otros que, aun remotos, nos son accesibles.

De otro, el fenómeno de la insumisión, no ya individual sino social e institucional, como revela la actitud administrativa ante la supuesta "objeción de conciencia" y la de los jueces ante la insumisión, capaz de desactivar el esquema actual de la defensa.

Tan arduos problemas no pueden dejar de tener reflejo en una interpretación de la Norma Fundamental que sea calificable, como señalara Maunz, de "constitucionalismo vivo".

En efecto, la Constitución puede entenderse desde dos perspectivas diferentes, aunque complementarias. La primera, la Constitución como norma que, entre otros extremos, organiza la seguridad del Estado. La segunda, la interpretación de la Constitución como proceso de integración del mismo Estado, integración que se autoafirma en la propia defensa y seguridad.

2. Si atendemos a la primera de estas dimensiones, el problema de la constitucionalidad de las Fuerzas Armadas profesionales se centra en el artículo 30 de la Norma Fundamental, según el cual:

1. Los españoles tienen el derecho y el deber de defender a España.

2. La ley fijará las obligaciones militares de los españoles y regulará, con las debidas garantías, la objeción de conciencia, así como las demás causas de exención del servicio militar obligatorio, pudiendo imponer, en su caso, una prestación social sustitutoria.

3. Podrá establecerse un servicio civil para el cumplimiento de fines de interés general.

4. Mediante ley podrán regularse los deberes de los ciudadanos en los casos de grave riesgo, catástrofe o calamidad pública. 
Para interpretar correctamente el citado precepto es necesario acudir a los criterios hermenéuticos establecidos para todo el ordenamiento por el artículo 3 del Código Civil, según el cual "las normas se interpretarán según el sentido propio de sus palabras, en relación con el contexto, los antecedentes históricos y legislativos y la realidad social del tiempo en que han de ser aplicadas, atendiendo fundamentalmente al espíritu y finalidad de aquéllas".

¿Qué nos dice la literalidad del art. 30 CE? Claramente, "el derecho y el deber de defender a Españan: lo único que la Constitución establece terminantemente no equivale a su defensa armada y, menos, exige un servicio militar obligatorio. La posible obligatoriedad del servicio militar sólo resulta del párrafo 2 del citado art. 30 y no precisamente como una imposición de la Constitución, sino como una remisión de la misma a la ley, que regulará tanto "las obligaciones militares de los españoles" como "la objeción de conciencia así como las demás causas de exención del servicio militar obligatorio".

En su contexto inmediato, por lo tanto, el servicio militar no es la opción de la Constitución, sino una de las alternativas que la Constitución prevé y respecto de la cual se remite a la ley.

Otro tanto resulta de los antecedentes históricos y legislativos. Esto es, del constitucionalismo histórico español y de la propia experiencia de quienes redactamos la Constitución.

En cuanto a lo primero, todos los textos, desde el de 1812 al de 1931 y el propio Fuero de los Españoles de 1945, establecieron una obligación cuya actualización correspondía determinar a la ley.

Ahora bien, es sabido que el Estado no necesita una habilitación especial para exigir ni tributos ni prestaciones personales, entre otras, la militar, como expresiones primarias de la soberanía. Luego su constitucionalización no se explica como una innecesaria autoatribución de potestad por parte del Estado, sino como introducción de una reserva de ley para garantía de los ciudadanos. Así ocurre en el caso de las prestaciones contempladas en el artículo 31.3 CE.

A la misma conclusión se llega si se atiende a la génesis en las Cortes de 1977 del texto vigente. El actual art. $30 \mathrm{CE}$ apenas fue modificado en los debates del Congreso y del Senado. Sus elementos redaccionales fundamentales fueron acordados en la Ponencia y allí el citado texto fue fruto de una propuesta de AP que se remitía a la ley para la determinación de los deberes militares de los españoles y de dos ini- 
ciativas, una del PSOE y otra de Minoría Catalana ${ }^{2}$. La primera, relativa sólo a la objeción de conciencia; la segunda, aunque mencionara la obligatoriedad del servicio en los términos fijados por la ley, en línea con la resolución de la Asamblea Consultiva del Consejo de Europa n. ${ }^{\circ}$ 37, de 26 de enero de 1967, en la que, aun reconociendo como principio general la obligatoriedad del servicio, se hace para cubrir una recomendación favorable al reconocimiento de la objeción de conciencia.

Por mi parte, como ponente constitucional puedo atestiguar que, sobre las propuestas mencionadas, nos atuvimos en UCD al criterio según el cual una cosa es el deber general de defender a la patria, incluso con las armas -aunque este extremo no se prevea-, algo, como después diré, de importancia radical, y otra el de prestar, si la ley así lo establece, el servicio militar, lógicamente mucho más accidental y secundario.

El mismo tenor tuvieron las enmiendas formuladas en el Congreso. La preocupación fundamental era la objeción de conciencia, y el servicio militar, por nadie discutido, siempre se consideró como algo a regular por el legislador. Así se deduce del propio Informe de la Ponencia de abril de 1977. Los debates del Congreso poca luz arrojan sobre un texto consensuado. $Y$ en el Senado no prosperaron las enmiendas, como las del Almirante Gamboa, de las que podría deducirse la obligatoriedad constitucional del reclutamiento obligatorio ${ }^{3}$.

En consecuencia, puede concluirse que la voluntad del constituyente no fue establecer la obligatoriedad del servicio, sino remitirse al legislador. Así lo avalaban los modelos de derecho comparado, en el que, cuando se ha querido imponer constitucionalmente el servicio militar, se ha recurrido a fórmulas mucho más imperativas, y a la inversa en otros casos. Baste comparar en este sentido la Constitución portuguesa de 1977, que ha de ser reformada para suprimir la obligatoriedad del servicio militar, con la fórmula de la Ley Fundamental alemana, en la línea en que la han interpretado autores como Volkmar Gotz o Hasso Hofmann ${ }^{4}$.

2 Los borradores aportados por los distintos grupos políticos a la ponencia han sido exhumados por Mercedes Rivas en su tesis doctoral, aún en elaboración, sobre "La génesis del Título I de la Constitución". Respecto del trámite de Ponencia, cfr. las Actas de 8 de septiembre, importantes a los efectos del texto (Revista de las Cortes Generales, n. ${ }^{\circ}$, pág. 270).

3 Cf. Constitución Española. Trabajos parlamentarios, Madrid, Cortes Generales, 2. ed., 1989, t. I, pág. 521, y t. III, pág. 3562.

4 Cfr. Veröffentlichungen der Vereinigung der Deutschen Staatsrechtslehrer, 41, 1983, págs. 23 y 70 . 
La experiencia de nuestro entorno, la "realidad social del tiempo en que la norma ha de ser aplicada", muestra que la desaparición del servicio militar obligatorio no está reñida con el mantenimiento de un compromiso global y operativo de la sociedad con la defensa nacional. Baste pensar en la experiencia británica posterior a la All Volunteers Force de $1957^{5}$.

Tales criterios permiten, como requiere el art. $3 \mathrm{CC}$, descubrir el espíritu y finalidad de la norma, en este caso del art. $30 \mathrm{CE}$. Una cosa es el deber general de defender a España (art. 30.1 CE) y otra las concretas obligaciones militares de los españoles, entre otras posibles, el prestar un servicio militar obligatorio. Respecto de éstas últimas se establece una reserva de ley como garantía, tanto general, reiterando la reserva que cubre todas las prestaciones personales (art. $31.3 \mathrm{CE}$ ), como específica respecto de la objeción de conciencia (art. 30.2 CE). Y así lo han reconocido, tras una vacilación inicial, tanto la jurisprudencia del Tribunal Constitucional, en su Sentencia 60/91, de 14 de marzo, como la doctrina más autorizada. Baste por todos, aunque la lista podría ser grande, citar el nombre del Letrado del Consejo de Estado, Dr. David Blanquer Criado ${ }^{6}$.

De lo expuesto cabe extraer ya dos conclusiones importantes. Por un lado, al ser el servicio militar obligatorio una de las posibles opciones del legislador, el reclutamiento forzoso no es un ingrediente sustancial de las Fuerzas Armadas. Por ello, aun si se admitiera la tesis según la cual el art. $8 \mathrm{CE}$ asegura a éstas una "garantía institucional» " con el alcance que a esta figura da el Tribunal Constitucional ${ }^{8}$, el servicio militar no estaría protegido por dicha garantía frente a la opción profesionalizadora del legislador ordinario.

Por otro lado, la objeción de conciencia, tutelada en el artículo 30 , se configura por el constituyente, no como un derecho, sino como una causa de excepción del servicio obligatorio, y sólo la jurisprudencia del Tribunal Constitucional le ha dado la condición de derecho ${ }^{9}$.

5 Cfr. Agullar y Bardaji, El servicio militar. ¿Obligatorio o voluntario?, Madrid, Tecnos, 1992, y el número monográfico de Política Exterior, 26.

${ }^{6}$ Ciudadano y Soldado. La Constitución y el servicio militar, Madrid, Civitas, 1996, págs. 48 y ss.

7 A partir de Trillo-Figueroa, "Las Fuerzas Armadas en la Comunidad Europea», en Revista de Estudios Políticos, n. ${ }^{\circ} 12$ (1979), págs. 105 y ss.

${ }^{3} \quad$ Cfr. STC 28 de julio de 1981, FJ-3.

9 Desde la STC de 23 de abril de 1982, tesis después recogida expresamente por el legislador. 
Volviendo a la cuestión central, parte de la doctrina ha planteado la cuestión de si del carácter democrático del Estado, sentado como principio en el artículo 1.1 CE, no se deduce la obligatoriedad del servicio militar universal para los varones e incluso para las hembras. David Blanquer ${ }^{10}$ ha dedicado largas páginas a impugnar esta tesis demostrando que la obligatoriedad y universalidad del servicio no es consecuencia de un principio dogmático como la democracia es, sino de las necesidades técnicas y económicas de la defensa en una época en que se han requerido ejércitos masivos cuyo coste profesional escapaba a las posibilidades de la hacienda. Pero esta aparente conexión entre democracia y obligatoriedad y universalidad del servicio sí nos pone en la pista de una más honda dimensión del tratamiento constitucional de la cuestión. Porque, en efecto, la movilización social que la democracia supone ha tenido lugar, históricamente, en términos militares y laborales fundamentalmente. Ahora bien, los términos de tal movilización, como históricos que son, resultan modificables en función de las necesidades y posibilidades culturales del tiempo, y así, mientras en un momento la defensa nacional pudo necesitar masas, en otro puede necesitar especialistas. Lo que sería contradictorio con las propias exigencias históricas es eliminar la conscripción obligatoria de las masas y no dotar de medios la formación y la tecnología que la especialización requiere.

Nada se opone, pues, en la Constitución, a la plena profesionalización de las Fuerzas Armadas. Lo que la Constitución impone, con enérgica pretensión de validez, es un deber general de los ciudadanos de defender a España, apodícticamente afirmado en el artículo 30.1, y esto si que se corresponde con el carácter democrático que del Estado predica el artículo 1 de la Constitución.

Pero, ¿en qué consiste este deber? Su incidencia militar, aunque no exclusivamente armada, es manifiesta en el propio artículo 30 , pero el contexto que la Constitución toda le proporciona, lo precisa.

Por de pronto, el artículo 8 formula un concepto constitucional de seguridad: la tutela de "la soberanía e independencia de España... [de] su integridad territorial y del ordenamiento constitucional». Éstas y no otras son las funciones de las Fuerzas Armadas y con ellas deberán conectarse todas sus misiones. No todas las "buenas acciones" propias de los boy scouts son las más idóneas para el guerrero. 
Pero, además, aun dando por supuestas las dimensiones políticas de la seguridad y sus componentes sociales, económicos y diplomáticos, la Constitución reconoce "la defensa militar como última ratio de la seguridad". Se trata de una opción de extraordinaria importancia del constituyente que, abandonando el Ilamado Derecho Constitucional de la Paz, reivindica el derecho de guerra (art. 63.3 CE). Tal vez no como instrumento de política nacional, y ello por razones no sólo jurídicas - la Carta de las Naciones Unidas-, sino también técnicas, de consecuencias anti Clausewitz; pero sí como garantía de la propia seguridad. Con ello la Constitución de 1978, que en tantos aspectos había seguido el modelo de 1931, paradigmático de aquella orientación, cambia de dirección y contribuye a decantar una nueva tendencia del derecho constitucional internacional, más realista que liberal, y que después había de ser seguida por más recientes constituciones ${ }^{11}$.

Ahora bien, lo que el principio democrático implica es que la seguridad, asi entendida y recientemente instrumentada, es tarea de todos. Una empresa popular, como reflejan las Reales Ordenanzas de $1978^{12}$. Si la defensa es tarea de todos $y$, haya o no servicio militar obligatorio, la ciudadanía no puede desvincularse de ella, la opción por unas Fuerzas Armadas profesionales ha de evitar también el riesgo del ejército pretoriano, esto es, desconectado de la sociedad ciudadana. $Y$ en ello insistiré más adelante.

3. Lo expuesto permite $y$ exige abordar el otro sentido de la Constitución como integración, y con ello avanzar por la segunda perspectiva atrás enunciada.

En efecto, la seguridad y su instrumento supremo, la defensa, aparece como una misión fundamental del Estado (artículo $149.1 \mathrm{CE}$ ), que afecta a su misma existencia como tal Estado. No en balde los elementos de esta existencia, que se enuncia en el artículo 8 CE como ingredientes fundamentales de la seguridad, son los que caracterizan al propio Estado en el artículo 1 de la Constitución. El Estado, para ser tal, "estable", debe estar y sentirse seguro. Por eso su Teoría General, a la vez que destacaba la esencialidad de los elemèntos del Estado tutelados en el art. $8 \mathrm{CE}$, ha hecho de la seguridad, con uno u otro nombre, su primordial y principal finalidad, y la economía política ha considerado la

"Cfr. Legaz Lacambra, "Las garantías constitucionales del Derecho Internacional (con especial referencia a la Constitución Española)», Revista de Derecho Público, 1933, págs. 30 y ss. Y Mirkine GuETZEVITCH, Derecho Constitucional Internacional, trad. esp., Madrid, 1936, pág. 317.

12 Arts. 2, 4 y 23. 
defensa como el bien público nacional típico. Esto es, aquel bien cuya producción ha de corresponder al Estado necesaria y exclusivamente. Porque es imprescindible para la comunidad y porque no hay seguridad sin que garantizarla sea tarea reservada al poder público. Que el Estado excluya aquí al mercado se debe, no a la hipotética falta de rentabilidad de las prestaciones privadas en la materia, sino porque la concurrencia, por plural y competitiva, es incompatible con la seguridad misma. La experiencia lucrativa y destructora de los mercenarios es prueba de ambos extremos. Es Leviatán, no Beemoth, quien proporciona seguridad.

Ello supone importantes opciones organizativas y presupuestarias, esto es, políticas. Y nunca mejor dicho de política de Estado, porque determinan qué Estado se quiere o, incluso, si lo que se quiere es un Estado.

La cuestión es si un Estado que proporciona bienestar y no seguridad, o llega a privatizar ésta, sigue siendo un Estado. El poder público, tras la ola neoliberal de las privatizaciones, continúa siendo empresario de la cultura y del ocio, asume la dotación de los partidos políticos y de los sindicatos y sustituye el ahorro privado por la previsión. Pero, a la vez, tiende a abandonar lo que el mismo Adam Smith consideraba sus misiones esenciales. Así, tiende a privatizar la justicia, las obras públicas e incluso la seguridad interior y reduce, drásticamente, sus compromisos en cuanto hace a la seguridad exterior. El resultado, de consumarse tal mutación de los fines del poder público, ¿sigue siendo un Estado? La llegada de Beemoth a la feria, ¿es compatible con Leviatán? Y si el Estado no es tal, no puede ser calificado por ningún adjetivo. No será, sin ser previamente Estado, ni de derecho, ni democrático, ni de bienestar.

Porque los bienes asistenciales así producidos son, por naturaleza, privados y sólo en cierta medida su garantía puede considerarse un bien público, mientras que lo definitorio del Estado es lo público, lo que atañe, no ya a todos, sino a la generalidad. Al cuerpo político como unidad existencial. Y éste es el caso de la soberanía, la independencia y la integridad, los valores que la seguridad y la defensa han de garantizar. De ahí que la seguridad, como expresión de la hondura existencial del Estado, remita al concepto de Constitución como integración.

Rudolf Smend ${ }^{13}$, un genial y riguroso profesor, puso de relieve que la Constitución es la ordenación jurídica del Estado, mejor dicho, de la dinámica vital en la que se desarrolla la vida del Estado, es decir, 
de su proceso de integración. La finalidad de este proceso es la perpetua reimplantación de la realidad total del Estado y la Constitución es la plasmación legal o normativa de aspectos determinados de este proceso. Y por integración entiende un uproceso de continua renovación y permanente reviviscencia", de configuración de un cuerpo político uno, a partir de la pluralidad social. Por eso, el Estado no constituye, en cuanto tal, una totalidad inmóvil, cuya única expresión externa consista en expedir leyes, acuerdos diplomáticos, sentencias o actos administrativos. Smend utilizaba la célebre caracterización de la Nación en frase de Renan; el Estado vive de un plebiscito que se renueva cada día. En esta acepción, la Constitución es no sólo una norma, sino una empresa permanente y colectiva sobre la base de un "vivir juntos" de la que la seguridad es el subsiguiente compromiso.

En consecuencia, lo que importa ante y sobre todo desde la Constitución, así entendida, es el mantenimiento del propio cuerpo político. De su soberanía, independencia e integridad; en una palabra, de su seguridad.

Sin duda no puede reducirse la política a la tensión existencial con el enemigo (Schmidt), como la vida excede con mucho el ser-parala-muerte (Heidegger). En esta reducción está el error del existencialismo, tanto filosófico como político. Pero el error consiste sólo en la reducción, sin que ello impida constatar que la finitud es un existencial del hombre, en cuya virtud cobra la vida individual consistencia, densidad y capacidad de sentido, y el cuerpo político conciencia de su propia identidad. La seguridad es, así, un existencial de la integración política, sustancia de la Constitución. No se trata, por lo tanto, de justificar constitucionalmente el imperativo de seguridad, sino que sin él no hay integración y, en tal caso, la Constitución sería, reiterando la cita de Triepel, un cascarón vacío.

Ello supone importantes consecuencias conceptuales primero y prácticas después. Baste pensar en lo que se ha denominado "sentimiento constitucional", noción de la que penden categorías jurídicopolíticas tan importantes como la de "lealtad constitucional», exigible no sólo a los ciudadanos, sino a las instituciones, y upatriotismo constitucional"s.

En nuestra sociedad actual la integración pasa por la opinión, y cómo ésta perciba y actúe el cuerpo político y las instituciones que lo articulan y expresan. Sin conciencia profunda de la identidad, ésta no existe; sin valoración, expresa o tácita, pero real y positiva, de las instituciones como factores de integración, tales factores no actúan; y sin 
voluntad de garantizar mediante la defensa la propia seguridad, no hay esfuerzo de seguridad posible. Una voluntad que, para ser eficaz, no puede ser gratuita, sino que ha de asumir riesgos, costes económicos, humanos y aun morales. La defensa de la propia seguridad no es un regalo. Supone ser consciente de los propios intereses vitales que, en caso de insuperable conflicto con terceros, han de ser defendidos por la fuerza. Requiere un esfuerzo económico que significa posponer, cuando no excluir, la satisfacción de otras necesidades, estimadas menos necesarias que la seguridad. Exige la disposición a sufrir bajas y, lo que es igualmente difícil, a causar víctimas. Implica, por lo tanto, importantes opciones éticas y económicas, tanto más difíciles cuanto que la percepción de la amenaza no es siempre igual y, en épocas como la nuestra, superada la Guerra Fría, tiende a disminuir.

Semejante conciencia ciudadana no se improvisa. Para que se dé a la hora de sostener el esfuerzo bélico heroico es preciso haberla cultivado largamente. Fueron, se ha dicho con razón, los campos de deporte de Eton los que triunfaron en Waterloo y los maestros de escuela de la III República en el Marne. Y después, la asociaciones implicadas en la defensa -ex reservistas, retirados, mujeres, etc. - han contribuido decisivamente a mantener viva en la sociedad la preocupación por las cuestiones militares y el apoyo social al esfuerzo defensivo. Otro tanto puede decirse de la atención de los medios académicos e informativos. Baste pensar en dos países como Gran Bretaña o Finlandia, para poner dos ejemplos bien diferentes en cuanto a potencia y responsabilidades, pero que revelan la misma actitud.

Ello lleva a concluir que la seguridad requiere el estado de conciencia que se llamaba "patriotismo". Esto es, el sentimiento de integración política, de pertenencia, no necesariamente exclusiva, pero sí preeminente y terminal, a una comunidad política, incluso si el esfuerzo de seguridad se canaliza a través de formas complejas, aunque no tan lejanas que diluyan el patriotismo que le sirve de motor.

¿Hasta qué punto ese sentimiento de integración coincide con el Ilamado sentimiento constitucional? $O$, en otras palabras, ¿cabe ahora y aquí otro patriotismo que el llamado, desde Habermas, patriotismo constitucional, esto es, la vinculación a la comunidad nacional en función sólo de la vigencia de determinados valores?

La cuestión no es baladí, porque de ella dependen los criterios rectores de la educación ciudadana. La Constitución, entendida como norma reguladora de derechos, distribuidora de competencias y organizadora de controles, o se queda al margen de la conciencia ciudada- 
na como una mera herramienta juridica, no distinta de la muy útil y poco emotiva Ley rituaria civil, o, de tomarse como pieza central de la educación ciudadana, daria lugar a la transmisión de valores meramente formales como los de tolerancia, coexistencia y respeto al libre desarrollo de la personalidad, fundamentales sin duda, pero insuficientes para activar el esfuerzo que la seguridad requiere. Si es difícil, además de dulce y honroso, morir por la patria, es imposible hacerlo por un orden jurídico abstracto en cuya virtud se garantiza la coexistencia de esferas de libertad, según reza la concepción filokantiana del Estado de Derecho.

La Constitución, entendida como integración viva de la que instituciones y derechos son factores, exigiría una educación ciudadana que, junto con los valores formales, transmitiera otros materiales $y$ sustantivos de los cuales será central la identidad del propio cuerpo político en el tiempo - los recuerdos y los proyectos comunes- y en el espacio -la integridad territorial- ${ }^{14}$.

El sentimiento constitucional, el patriotismo constitucional, sólo es relevante si la Constitución es integración de la unidad política, e integración tan intensa que la seguridad y la defensa, incluso armada, de la misma, es una de sus existenciales. El sentimiento constitucional sería asi compromiso patriótico.

El cultivo del patriotismo, asi entendido, ha de evitar dos alternativas opuestas e igualmente estériles desde el punto de vista de la seguridad. Egoísmo de lo concreto y altruismo de lo universal. No en balde, el Estado nacional -o plurinacional, pero integral- es el universal concreto por excelencia. Como ha subrayado Luis Díez del Corral $^{15}$, la Nación es, histórica y lógicamente, la dimensión en la que se encarna lo universal y se transciende lo inmediato.

No se puede sustituir esta conciencia de integración por la egoísta defensa de unos determinados privilegios o ventajas comparativas, tales como el propio modo o nivel de vida. Nadie muere por conservar su comodidad, porque cualquier incomodidad es preferible a la de morir. "Antes rojos que muertos", fue durante largos años el lema de los hedonistas "progres" de Europa Occidental. La patria no es donde se está mejor, sino que el ciudadano sabe que donde se está mejor es en la patria.

14 Sobre este último aspecto, cfr. mi estudio «El territorio nacional como espacio mítico", en Libro-Homenaje a García Pelayo, Caracas, 1979, págs. 629 y ss.

15 El rapto de Europa, pág. 253 (cito 2.a ed., Madrid, 1962). 
Cuando, como en el caso de España, el concepto de patria se complica con la plurinacionalidad del Estado, a una Constitución integradora a fuer de plural y a un patriotismo supranacionalista han de corresponder unas Fuerzas Armadas cuya composición refleje esa misma plurinacionalidad. Y eso es garantía de su unidad. Nada más contrario a ésta que la hipótesis de una oficialidad sólo castellana. La experiencia de la supremacía serbia en el Ejército Federal vugoslavo es prueba de ello.

De otro lado, tampoco puede sustituirse la percepción de la ame- . naza concreta por un altruismo universal que haga de la defensa de la paz y el orden internacional la motivación de una política de defensa y seguridad. Restablecer y guardar la paz al servicio de las Naciones Unidas puede ser importante tarea en beneficio de la propia seguridad, y ello por múltiples razones. Pero han de ser explicadas a la opinión pública en función de tal seguridad propia y no como mera contribución al bienestar de la comunidad internacional. Cuando la opinión se resiste a esforzarse en defensa propia, ¿no sería extraño e incluso sospechoso que lo hiciera por la ajena?

La Constitución, como Norma Fundamental del ordenamiento, se caracteriza por su apertura a la integración internacional (art. 93.1); pero ello no excluye su supremacía (art. 95) y, en tal sentido, se ha pronunciado la más solvente doctrina y jurisprudencia española y comparada.

Análogamente, la integración política que la Constitución supone y que a la Constitución vivifica, no es excluyente de otros sentimientos, pero en lo político ha de ser preponderante si la identidad política ha de existir y subsistir. $Y$ esta identidad terminal y existencial ha de motivar la defensa, incluso armada, de la propia seguridad. Ello aconsejaría ser muy cuidadoso a la hora de proponer formas supranacionales de defensa. Es claro que en nuestros días la seguridad, para ser eficaz, ha de ser colectiva y que en su colectivización en cuadros europeos y atlánticos está el más prometedor horizonte de la seguridad española. Pero la seguridad como su base, la integración política, no es una mera cuestión mecánica, sino sobre todo afectiva, y los afectos no son fungibles. De ahí que la colectivización de la defensa no debe prescindir de los factores simbólicos, espaciales, institucionales e históricos que la hacen integración en acto supremo. Por eso, las fórmulas que, como la OTAN, hasta ahora, han compatibilizado los ejércitos nacionales con la estructura integrada de mandos, sean más sólidas que otras fórmulas de plena integración en unidades plurinacionales. 
A la inversa, sin un cuerpo político capaz de autodefenderse que, como carne, fundamenta la epidermis constitucional, las disposiciones constitucionales serían papel mojado. Así ocurrió, señala Jellinek, en un texto clásico ${ }^{16}$, con aquellas constituciones que dejaron de movilizar los afectos -lealtades, pasiones y ambiciones-políticas. La seguridad no es, pues, una obligación que la Constitución impone. Es una condición sin la cual la Constitución se extingue.

La historia, laboratorio de las ciencias sociales, muestra que, desde Pericles a la Guerra Fria, las democracias se han caracterizado por su vocación y capacidad para la defensa. Y la razón lógica es que la democracia no florece fuera de ese biotopo que es el cuerpo político, el "body politic" de los anglosajones; hoy, por excelencia, la Nación. Pero la Nación sólo vive del esfuerzo y los sacrificios que es capaz de solicitar y obtener de sus ciudadanos y el esfuerzo bélico-heroico es su paradigma. Sin deber militar de la ciudadania no hay cuerpo político, ni democracia, ni Constitución.

Ahora bien, el correlato de todo ello es que, como antes señalé, las Fuerzas Armadas no sean ajenas al "cuerpo político". Tal fue el caso $y$ es el prototipo de los pretorianos, y en precaverse contra tal riesgo insisten las Reales Ordenanzas vigentes. Pero no se trata de una cuestión fácil de resolver, ni en una sociedad democrática ni con unas Fuerzas Armadas estrictamente profesionales. Porque si el riesgo de la estamentalización militar, en el sentido que Weber diera al término, siempre ha existido, es aún mayor cuando la sociedad es plural y cambiante y falta el nexo popular que el servicio militar universal y obligatorio supone, y los ejércitos, sin dejación de sus propios valores, han de estar en consonancia con los valores vigentes en aquella sociedad.

$\mathrm{Si}$ los valores estrictamente castrenses excluyeran a los generales de la sociedad a la que el Ejército tiene que servir, éste se estamentalizaría primero y terminaría siendo un cuerpo diferente al general de la Nación y, en consecuencia, un Estado en el Estado. Pero si ocurriese a la inversa y el Ejército perdiera sus propios valores y se laboralizara como si se tratase de un colectivo más de trabajadores del sector público, resultaría ineficaz cuando no igualmente peligroso. Quienes se alquilan para dar la vida, suelen preferir cobrar el alquiler $y$ sacrificar la vida ajena. El riesgo mercenario no es, pues, menor que el riesgo pretoriano.

16 Reforma y mutación de la Constitución, trad. esp., Madrid, 1991, pág. 57. 
Superar tales Escila y Caribdis de la integración militar en el cuerpo político exige toda una toma de conciencia castrense de la propia tradición y de su inserción en la tradición española, democráticamente actualizada y proyectada en servicio más heroico que laboral. De autocomprensión de su función, mejor como misión que como profesión, y ello será tanto más necesario cuando más profesionalizadas estén las Fuerzas Armadas.

Las consecuencias prácticas de lo expuesto son varias e inciden muy especialmente en la formación castrense y en el status del militar, no sólo jurídico sino también social. Si es lógico que al militar se le prive de ciertos derechos para garantizar la eficacia interna de las Fuerzas Armadas y su plena despolitización, no lo sería menos que el prestigio de la carrera militar, la solvencia de sus instituciones de apoyo y la favorable acogida por parte de la sociedad civil de quienes abandonan honrosamente el servicio activo, equilibrase aquellas limitaciones. Así ocurre en los países con más sólida tradición democrática y mejores Fuerzas Armadas.

Pero articular tales extremos con categorias jurídicas plantea una última cuestión que no cabe aquí sino enunciar. Se ha discutido largamente si los Ejércitos son, hoy en España y sobre la base del art. $8 \mathrm{CE}$, una institución o, simplemente, un sector de la Administración, como podría deducirse del art. 97 CE. No es ésta la ocasión de entrar en la polémica, que puede resultar estéril si de ella no se deducen consecuencias prácticas ${ }^{17}$. Por mi parte, prefiero recurrir a la categoría de "orden concreto" que Schmitt formulara para superar la disyuntiva entre normativismo y decisionismo como criterios de interpretación constitucional. Es el orden concreto, como entramado de relaciones constitutivas de un conjunto, lo que permite entender la índole de las Fuerzas Armadas y también, dicho sea de paso, de la administración civil y de sus grandes cuerpos si éstos han de conservar el espíritu diferencial que garantiza su capacidad de servicio.

Este haz de relaciones que es el orden concreto supone unos valores peculiares que pueden no coincidir con los de la sociedad civil, precisamente para poder servirla con una especial capacidad. Pero de estos valores, el primero es, sin duda, esa voluntad de servicio a la so-

17 Por un lado, Trillo en el trabajo ya citado; por otro, López Ramón, La caracterización jurídica de las Fuerzas Armadas, Madrid, 1987, como posiciones más representativas. Cfr. BLANCO VALDÉS, La ordenación constitucional de la Defensa, Madrid, 1988, págs. 65 y ss. 
ciedad, como la sociedad quiera ser servida y así lo exprese por los cauces legalmente establecidos, $y$, además, son valores que no pueden exigirse a la sociedad entera, aunque la sociedad hará bien no sólo en respetarlos, sino en estimarlos. Si no es así, la profesionalización de las Fuerzas Armadas será o imposible — por falta de voluntariado-o peligrosa - por carencia de la ética especial que exige la especialisima función de monopolizar la fuerza y utilizarla al servicio de la seguridad del cuerpo político-.

De ahi que la profesionalización de las Fuerzas Armadas, considerada desde el punto de vista constitucional, tenga varios sentidos.

Sí a unas Fuerzas Armadas profesionales, en correspondencia a las necesidades de la defensa y a las posibilidades de la hacienda española.

La obligatoriedad del servicio militar dependerá, en consecuencia, de la opción política del legislador ordinario, cuya corrección constitucional dependerá de su respeto a los valores de la Constitución.

No a un ejército mercenario que pudiera ser pretoriano, ajeno al cuerpo político.

No a que la desaparición del servicio militar obligatorio lleve a un desentendimiento de la opinión pública con respecto a la defensa.

Si a una capacidad de movilización general cuando ello fuera necesario.

Y sí a lo que la hace posible: una promoción de la integración del cuerpo político, capaz de morir por la patria un día, porque sabe vivir todos los días para ella. 